\title{
Strategies for Private Sector Participation in Child Healthcare: A Meta Analysis of Empirical Findings
}

\author{
Suneeta Sharma
}

\section{Introduction}

A large number of households in developing countries seeks child health care services from the private sector. Despite this, policy makers have largely ignored it while developing health policies. Without an effective stewardship of government, the technical quality of child healthcare services provided by the private sector has generally remained poor. In this context, there is a growing consensus that a better match between the role of public and private sectors and their respective capabilities needs to be established. In such a redefined role, the public sector would largely perform a stewardship function and create an environment in which the private sector can help the state achieve its goals in the health sector.

This raises a number of policy issues: how governments can fulfill their stewardship function in the context of child health, how they can work with the existing private sector to improve the effectiveness of child health services, and how they can encourage further private sector participation in the delivery of child health care services. Policy makers and analysts usually possess little knowledge or understanding of the private sector. In addition, the strategies and instruments to "harness" and "grow" the private sector for the achievement of child health objectives are not widely studied, or understood. This paper provides an overview of reform strategies and instruments being utilized in developing countries to enhance the contribution of the private sector to child health care.

\subsection{Objectives}

The paper uses an analytical framework to gather and analyze information about public-private partnership programs, the effectiveness of these programs, and to identify the areas for future work on public-private issues in child health care. The paper is based on a review of 130 relevant studies, both published and unpublished.

\subsection{Analytical Framework}

The paper uses an analytical framework to help health policy makers and planners identify policies to:

Work with the private sector to ensure that the services it provides meet health sector goals (harnessing the private sector);

Create an environment that supports private sector growth consistent with child health goals (growing the private sector).

Certain principles of public finance and institutional economics guide the public-private division of labor. These principles also set out the stewardship role of the public sector in guiding (the often much larger) private sector in financing and provision of child health services.

These principles help clarify the rationale for effective mix of public and private sectors in health care goods and services and marking out their specific domains. According to these principles, a desirable division of labor between public and private sectors in health depends on whether markets can work properly (contestability), so that the private sector will produce positive results, and whether information is sufficiently available (measurability) to permit assessment of the effectiveness of services. When markets and information fail, governments must play a corrective role. When markets and information succeed, government can open space for private response to consumer demand. As these conditions differ from time to time and place to place, the relative roles and relations of private and public sectors must evolve as well (For detailed description of the framework and the associated principles see, Chakraborty and Harding, 2001 pp.5-8). 
Both theory (level of contestability and measurability) and available empirical evidence suggest that a majority of goods and services can be adequately produced and delivered through the private sector, provided the public sector performs its function of creating enabling conditions for private sector participation and appropriate regulatory roles.

Governments can use a variety of instruments including financing, regulation, provision of information, and mandates to correct the failure of markets (Musgrove, 1996). These instruments fall within the domain of the stewardship function of the public sector. Stewardship is the key function of the public sector and has been defined as a "function of a Government responsible for the welfare of the population and concerned about the trust and legitimacy with which its activities are viewed by the citizenry (WHO, 2000)". Effective stewardship creates supportive environment for the involvement of health sector stakeholders such as purchasers, providers, and consumers. It also influences the behavior of these key stakeholders to ensure their greater contribution towards the achievement of desirable outcomes.

Governments perform their stewardship functions to harness the private sector by using three instruments, namely application of financial incentives, regulations, and information dissemination. They provide financial incentives through contracting, indirect public finance, and insurance regulation in order to influence the behavior of the private sector. Regulation involves government actions and policies to influence the activities and priorities of the private sector and prevent market failures. Information dissemination entails the use of both education and persuasion to change the behavior of providers as well as patients in ways that improve child health care services. Stewardship functions also include expanding the private sector in certain areas or sub sectors either through "growing" the private sector or "transferring" some activities currently in the public sector to the private sector. Through this, they encompass and exploit the existence, capabilities, and potential of both the public and the private sectors - especially in service delivery. It involves identifying easy win activities in which the private sector can perform more productively and creating an enabling environment for its growth. It facilitates the use of scarce government resources on priority interventions and objectives.

\subsection{Application of the framework to child health}

Figure 1.1 summarizes the analytical framework in the context of child health care.

\subsubsection{Emerging issues}

Increasingly, policy makers and analysts in developing countries are taking notice of the role of private sector in delivering child health care services. This is because governments alone cannot meet the growing child health care demand, the private sector has already a major stake in child health care service provision, and because of the changing perspective in favor of greater interaction between public and private sectors for enhancing quality and preventive care services.

\subsubsection{Redefining the public sector role}

The role of governments in providing child health care remains extremely important despite the overwhelming presence of private sector. Governments' effective stewardship role can ensure the private sector's positive contribution to child health. The degree of contestability, measurability, and information asymmetry of child health care services and goods can be used to determine the use of different instruments such as regulation, financing, information dissemination, and mandates. For example, the delivery of child health care services has high contestability.

Information dissemination function is particularly useful in promoting healthy behaviors among the community, improving case management practices of private practitioners through training, and implementing advertising campaigns through government media. Government mandates and regulations can be useful in guaranteeing the quality of child health care services. Regulatory reforms need to be implemented in combination with other regulatory instruments such as financial incentives and information dissemination. For example, self-regulation, periodic renewal of personnel licenses, accreditation of practitioners and facilities, enactment of consumer protection laws, and generation of awareness on rights of consumers are appropriate regulatory measures in the context of child health care services. Public financing is a powerful instrument for affecting the behavior of the private sector. Direct and indirect financial incentives specific to child health services include: extension of 
government's free insurance to cover immunization services provided by private providers; provision of free vaccines to the private sector as an incentive to deliver immunization services; easing of restrictions on advertising of child health products; and mandated inclusion of child health care services in health insurance policies.

\subsubsection{Reform strategies to promote child health care}

A review of the reform strategies reveals two alternatives: governments opt to focus on enhancing the contribution of the existing private sector and/or they opt to expand the private sector in certain areas. As the private sector is already the dominant provider of child health care services, the "harnessing" or guiding of existing private providers is more important than growing private sector/privatization. As the private child health care market comprises non-governmental organizations, for-profit, and not-for-profit health care providers, and commercial sector, government use various instruments to guide, enable, motivate, and influence the private sector (See Figure 1.2). The analytical framework suggests focused and strategic use of scarce government resources.

\subsection{Organization of the Paper}

Following this introduction, Section 2 assesses the need to mobilize private sector for child health care. Section 3 reviews successful strategies to harness the private sector and the instruments used for their implementation. Section 4 discusses different mechanisms and instruments used to expand the private sector in child health. Section 5 presents potential actions for effective and sustainable private sector participation. Section 6 presents key policy and implementation issues. Section 7 discusses information gaps and future research needs.

\section{Need to Mobilize the Private Sector}

Increasingly, policy makers and analysts in developing countries are taking notice of the role of the private sector in delivering child health care services. This is because governments alone cannot meet the growing child health care demand (Sec. 2.1); the private sector has already a major stake in child health care service provision (Sec. 2.2); and because of the changing perspective of the international community in favor of greater private sector participation (Sec. 2.3).

\subsection{Inability of the Public Sector to Meet Child Health Care Needs}

Low-income countries are increasingly recognizing that the available resources are not sufficient to meet the growing health care needs of children. A large number of children still die from preventable and treatable diseases.

* According to the World Development Report 1993, about 49 percent of disability-adjusted life-years (DALYs) lost in India are attributable to morbidity and mortality among children aged 0-4 years (World Bank, 1993).

* In developing countries, about 12 million children under five years of age die each year. Seventy percent of these early deaths occur because of five preventable conditions: diarrhea, acute respiratory infection, malaria, measles, and malnutrition (BASICS, 1999).

* Nearly three million children die each year from vaccine preventable diseases. About 30 million children $(23 \%$ of the total) do not receive any kind of vaccination (WHO, 2000).

\subsection{The Private Sector Role in the Delivery and Financing of Child Health Care}

\subsubsection{The private sector is used extensively for child health care}

In developing countries, the private sector plays a major role in the treatment of childhood diseases such as diarrhea, respiratory infections, malaria, and others by producing, distributing, and marketing public health commodities. For example, about 80 percent of registered doctors in India work in the private sector (Bhat, 1997).

* In developing countries such as Bolivia, Guatemala, Indonesia, and Paraguay, more than 50 percent of acute respiratory infections and diarrhea cases are treated in the private sector (Berman et al, 1994).

* In urban and rural India, more than 80 percent of households go to private health care practitioners for childhood illnesses (Chakraborty, 1998). Ninety-three percent of diarrhea cases are treated in the private sector (Northrup, 1997), and only 30 to 35 percent of patients receive ORS from the public sector; the remaining 65 to 
70 percent go to the private sector, of which between three and thirteen percent receive ORS from largely unlicensed private practitioners in rural areas (Rohde, 1997).

Clients spend relatively large amounts of money for curative services in the private sector, demonstrating a willingness to pay for easy access, high-quality services, and the confidentiality that the private sectors offers.

\subsubsection{Even the poor use private sector services substantially}

Many recent surveys indicate that low-income women and children in developing countries use private providers (see Box 2.1). They also spend a greater proportion of their income on health care than do high-income women and children.

An analysis of DHS data for 44 countries shows:

* Sixty-six percent of the poorest quintile of the population in the Dominican Republic obtained treatment for acute respiratory infections (ARI) from private facilities (see Figure 2.1)

* In Zambia, 52 percent of the poorest quintile obtained treatment for ARI from public facilities (see Figure 2.1), compared with 18 percent of the richest quintile (Gwatkin et al., 2000).

\subsubsection{High out-of-pocket expenditure on child health care}

People in developing countries already spend a considerable sum on private child health care (see Figure 2.2).

* A recent survey conducted in the Udaipur district of Rajasthan, India, shows high out-of-pocket expenditure on child health care both in rural and urban areas.

- About 81 percent of respondents paid for child health care even in public sector health facilities.

- Medicines constituted the majority of expenses (63\%), followed by consultation (21\%) and transport (14\%) (Hotchkiss et al., 2000).

* For the developing world as a whole, private households account for roughly one-half of all health spending, ranging between 30 and 60 percent across countries (Rosen et al., 1999)

* Household out-of-pocket expenditure accounts for about 75 percent of the total health expenditure in India (World Bank, 1997).

* In Vietnam, 68 percent of health financing comes from the private sector; the private sector's contribution in provisioning health care services is about 50 percent (Krasovec et al., 1999)

* A recent analysis of sources and uses of $\mathrm{RCH}$ finances indicates that household out-of-pocket expenditure accounts for about 78 percent of the total child health care expenditure in Rajasthan, India (Sharma et al., 2000).

* A review of five developing country studies shows that the poorest quintile spent 15.5 percent of its household income on health care compared with 5.2 percent spent by the richest quintile (Fabricant et al., 1999).

\subsection{The Changing Perspective on the "Role of State"}

Numerous international organizations including the World Bank, UNICEF, USAID, and WHO are acknowledging and championing greater interaction between the public and private sectors. The World Bank's 1993 and 1997 reports advised governments to target efforts and resources to preventing market failures in health care by restricting the use of resources for goods and services with positive externalities, such as immunization, and by addressing information asymmetry. These international agencies are also recognizing, and advocating for, the need for greater public-private interaction and redefinition of public sector roles (see Box 2.2).

Experience in most countries supports increasing private sector participation in child health care. Moreover, the private sector's role is well established and accepted both by society and government. Encouraging the private sector to play a greater role would allow governments to refocus their efforts to reach the poorest and most remote populations.

\section{Harnessing the Private Sector: Strategies and Instruments}

This section reviews the first reform strategy - harnessing the private sector for child health care - and the instruments used for its implementation. It reviews the prevailing mechanisms and instruments through which 
governments exert influence over the private sector by classifying them under three categories: financial incentives, regulation, and information dissemination (See Table 3.1).

\subsection{Financial Incentives}

Proper incentives and adequate information are two powerful tools to improve system performance by involving the private sector. Governments often provide financial incentives through contracting, indirect public finance, and insurance regulation in order to influence the private sector behavior. The most prevalent mechanism and the one that has the greatest impact is outsourcing health care services.

\subsubsection{Outsourcing child health care services}

Developing countries are harnessing private sector resources by contracting out government health services. Outsourcing government health services enhances the "efficiency of both provider and purchaser via the incentive structure inherent in the contract" (Palmer, 2000). Such an arrangement gives financial incentives to private sector providers by ensuring demand for their services. Involvement of the private sector also makes publicly funded services more accountable, transparent, and efficient.

\subsubsection{Benefits of Contracting}

Outsourcing has the potential to generate substantial gains in efficiency by securing services of comparable or higher quality at lower costs and by harnessing contractors' ability to fill temporary or permanent gaps in government capacity.

Contracting out clinical services to the for-profit private sector is a common practice in developing countries, but evidence of governments' purchasing NGO-provided services is limited. NGOs might be more tightly supervised and supported through contractual agreements, which could tie government funding to conditions, such as the level of services to be provided. "Contracting out health services to NGO sector can be a means to guard against 'government failure' by removing politics from the process of delivery, while ensuring that key decisions, such as determination of total funding levels, the overall service strategy, and the specification of service delivery, remain in the public sector" (Marek et al., 1999).

A recent study in Zimbabwe on government outsourcing of clinical health services to churches suggests that contracting out to church providers may even generate gains in technical efficiency (Gilson et al., 1997).

\subsubsection{Key success factors for Contracting}

In most developing countries, contracts are promoted despite the weak capacity of markets and governments to manage them, thus negating the benefits of the outsourcing. Gains in efficiency realized through contracting depends on numerous conditions, including, but not limited to:

- Government's ability to negotiate, implement, and monitor contracts

- Adequacy of information on government production costs, as well as those of competitors

- The presence of actual or potential competition (Broomsberg et al., 1997).

\subsubsection{Child health care activities contracted out}

Some typical government-contracted services include

- Preventive services, such as well-baby clinics, provided by missionary health centers and hospitals

- Immunization and other preventive services provided by some industrial and agricultural companies to workers and their families

- Community nutrition projects in Senegal and Madagascar for malnourished children. These projects used a contract management approach and provided preventive services through the private sector, outside the dominance of public health care professionals (Marek et al., 1999).

\subsubsection{Contracting strategies}

Few examples exist of the government contracting out preventive services. Two examples include well-baby clinics provided by missionary health centers and hospitals, and immunization and other preventive services provided by some industrial and agricultural companies to workers and their families (See Box 3.1). 
Community nutrition projects in Senegal and Madagascar reached a large number of malnourished children by implementing the contract management approach (See Table 3.2). Both projects successfully provided preventive services through the private sector, outside the dominance of government health sector (Marek et al., 1999).

\subsubsection{Other direct and indirect financial incentives based strategies}

An alternative to directly contracting for services is to indirectly support the demand or consumption of targeted child health care services.

\subsubsection{Providing tax breaks and subsidies for increasing the coverage}

Provision of incentives and support of innovations ensure that the private sector can grow to its full potential and provide quality services to the poor at the same time. Providing tax breaks and subsidized capital are two commonly used incentive schemes in practice that increase health coverage, particularly in underserved areas.

* Subsidies to increase market penetration and affordability of health care

By using product and market subsidies and removing import and local taxes, developing countries can make specific services and products more accessible and affordable to the private sector. For example, liberalization in Tanzania and pro-private sector policies in Rajasthan, India, led to increased participation of the private sector in both provision and financing of health care including child health care (Munshi, 1997; Winfrey et al., 2000) (See Box 3.2).

* Tax advantages on important ingredients and materials

A recent survey of the tax treatment of three public health commodities - vaccines, ORS, and contraceptives - in 22 countries found that specific tax relief arrangements are in existence and that vaccines receive the most favorable tax treatment (i.e. exoneration of most types of taxes for the greatest number of purchasers) (Krasovec et al., 1998). In almost all developing countries, government regulatory bodies give preferential tax and import treatment to "essential drugs."

* Encouraging investments through tax breaks

- The Board of Investment in Thailand helped establish new private hospitals by providing tax breaks (Bennett et al., 1997).

- Pakistan has been successful in using tax incentives to convince private primary health care providers to set up operations in rural areas (Bennett et al., 1997).

\subsubsection{Joint Investments as means to increase capacity and reach}

Joint investments are a non-regulatory means to influence private sector behavior. In exchange for investment, governments can claim a certain percentage of beds for poor patients (Newbander et al., 1997). In 1997, the Government of Delhi, India, proposed joint venture schemes under which the government contributes part of the equity capital of the proposed organization in the form of land. The proposal indicates that the government's contribution should not exceed 26 percent of the share capital. In exchange for its contribution, the government expects the private sector to provide free care to a certain percentage of poor (about 30-40\%) patients and participate in government public health programs (Bhat, 2000).

\subsubsection{Subsidizing costs of operations to increase viability of private health care providers}

Donors and governments provide financial support to encourage NGOs that meet priority health needs of the target group. Often, this support is provided to meet operations and maintenance expenses for sustaining service delivery (See Box 3.3).

\subsubsection{Using government resources to increase coverage}

Some governments have provided resources to the private sector, resulting in increased coverage. Governments have provided -

- Various incentives, such as free airtime on government-managed media (Slater and Saade, 1996)

- Free vaccines from government sources (See Box 3.4).

\subsubsection{Other examples}

Other direct and indirect financial incentives include - 
- Public subsidies and tax exemptions for health care providers

- Extension of government's free insurance to cover immunization services provided by private providers

- Channeling of donor funds to the public through NGOs

- Use of joint investment programs to spur private-provider involvement in underserved areas

- Provision of free vaccines to the private sector as an incentive to deliver immunization services

- Easing of restrictions on advertising of child health products

- Mandated inclusion of child health care services in health insurance policies.

\subsection{Regulation of Producers and Providers}

This sub section reviews a range of regulatory instruments for influencing the behavior of private health providers. It outlines prevailing strategies for putting pressure on private health providers to improve sector and provider performance.

\subsubsection{The need for government regulations}

Because governments and international agencies have substantial influence over private child health care market, government regulations can alter the behavior of the private sector and prevent market failures. Government actions and policies influence the activities and priorities of the private sector in many ways. For example, - Government drug regulatory authorities approve the production, importation, and marketing of drugs on a national scale, thus influencing the marketing, distribution and promotional activities of the drug industry; - Price and quality regulations protect clients against malpractice, monopolistic exploitation, and unreasonable escalation of prices;

- Government mandates and regulations guarantee good quality by setting service delivery standards for private providers, certifying the appropriateness of drugs and medical procedures, providing investment subsidies, and providing information (Bloom, 1999).

\subsubsection{Types of regulations affecting the private health care}

Governments often focus on laws that do not address implementation, incentives, and capacity. Government regulations commonly cover (Bennett, 1997)

- Aspects of quality-of-care, such as entry to the market (licensing) and use of hi-tech equipment

- Competitive practices, such as advertising, a patient's right to change doctors, the right of primary practitioner to sell drugs, and so forth

- Various aspects of market structure, such as the relationship between primary-level practitioners and hospitals

- Occasionally, regulation of health care fees.

\subsubsection{Laws and regulation-based strategies}

When governments remove unnecessary limits on the for-profit sector, they encourage it to increase its participation in child health care. Since the private sector comprises a wide range of players, governments need to specify carefully what their policies will promote and what they will restrict (WHO, 2000).

\subsubsection{Lowering legal and regulatory barriers}

Countries such as Malawi, Mozambique, and Tanzania have been successful in increasing private sector participation by eliminating unnecessary regulatory practices (Bennett et al., 1997). Some successful strategies and policies adopted by developing countries include -

* Relaxing state-imposed restrictions on the use of revenue for health care - One initiative that has recently received a considerable amount of attention is the introduction of Medicare Relief Societies (MRS) in Rajasthan. MRSs are autonomous organizations that aim to complement and supplement existing service provision in public hospitals. The state provided incentives to form these societies by relaxing state-imposed restrictions on the collection, retention, and use of revenue by hospitals, thereby encouraging the use of alternative financing mechanisms, such as user-fee schemes and in-hospital pharmacies. In addition, both the Ministry of Health and the Ministry of Family Welfare demonstrated a high level of commitment toward revenue generation, privatization, and managerial flexibility by granting essential autonomy and providing societies with seed money (Sharma et al., 2001);

* Increasing product choices for public health - In many countries, existing laws and regulations limit the population's access to child health care services and products. Some countries are loosening the regulations and 
controls on sale of public health products in order to increase access to these products. For example, in SubSaharan African and Latin American countries, private pharmacies provide immunizations after obtaining approval to sell vaccines from the government (Slater and Saade, 1996)

\subsubsection{Facilitating self-regulations among competing entities}

In health care markets where large NGOs and for-profit health care providers compete for clients, quality is critical to retaining clients; consequently, competing entities are not averse to self-regulation. Governments can encourage this practice by influencing the rules and regulations governing standards and norms for health care services and by subsidizing technical training and data systems that facilitate self-regulation. Some successful examples of self-regulations are as follows:

* PROSALUD self-regulates for quality and abides by the standards set by the MOH (Krasovec et al., 1999)

* Under an NGO umbrella, the public and private sectors can jointly undertake regulatory functions with the NGO performing ratings and watchdog functions (Box 3.5).

\subsubsection{Enforcing regulatory controls to ensure safe and affordable private services}

Because the heterogeneity of service providers and the wide range of services make regulation difficult, governments should implement a legal and regulatory framework that stimulates safe and affordable private services. An unregulated private sector leads to serious quality and equity problems. "The private sector is, to a large extent, motivated by profit, which sometimes leads it to ration care to those whose willingness and ability to pay allows providers to make a profit" (Bloom, 1999).

Though private health facilities generally offer higher-quality care and operate more efficiently than their public sector counterparts (Rosen et al., 1999), in many countries there are legitimate concerns regarding the quality and cost of services provided by the private sector. Government mandates and regulations can be useful in guaranteeing quality by setting service delivery standards for private providers and by certifying the appropriateness of drugs and medical procedures (Bloom, 1999). Wherever governments were unable to enforce such regulations, the private sector performed badly.

* Periodic renewal of personnel licenses is an effective regulatory mechanism. It forces private practitioners to maintain high quality standards and up-to-date knowledge.

* Accreditation of practitioners and facilities by professional bodies to conform to a defined minimum quality standard promotes informed decision making at the consumer level. In such programs, providers' skills and physical facility are assessed, accredited (assigned quality ratings), and promoted among potential users. 3.2.3.4 Enacting consumer protection laws and raising awareness of consumer rights Consumer interests and rights are weakly protected in most developing countries. Widescale promotion of the notion of "patients' rights" and establishment of a mechanism to investigate violations quickly and fairly can help safeguard consumer rights effectively (WHO, 2000). For example, consumer protection legislation is used as a means to protect consumers in India from private provider malpractice and negligence (See Box 3.6). To implement regulations effectively, patients, providers, and the media must know about these rules and regulations.

\subsubsection{Introduction of exemption schemes for poor children}

During the last 20 years, as the value of the world economy increased exponentially, the number of people living in poverty grew to more than 1.2 billion, including more than 600 million children (UNICEF, 2000).

Governments could introduce exemption schemes for priority target groups to ensure equity (See Box 3.7) and offer low-cost or free care to poor children. Both the public and private sectors may offer priority health services, such as immunizations, free-of-charge to all children. A survey conducted by Initiatives indicates that low-income women and children in Ghana already use private providers. A large number of private clinics discount or waive the fee for up to one-third of their patients (Sclafani, 1997).

However, user fee without an effective mechanism of exemptions is not recommended. The WHR 2000 identifies out-of-pocket payment as the most regressive way to pay for health, and the way that most exposes people to catastrophic financial risk. 


\subsubsection{Government's capacity to initiate and maintain an effective regulatory system}

Governments often lack the capacity to initiate and maintain an effective regulatory system that has legislative authority, a strong organizational structure, and the ability to monitor the use and quality of health care services (Newbrander et al., 1997). The complex structure of the health care market, with a large number of formal and informal providers, diverse distribution, and low capital investment coupled with generally poor public records and registration, makes the government's regulatory role both difficult and challenging (Rosenthal et al., 1997). Corruption is a major factor in a government's ability to carry out its assumed responsibility, including regulation. Centralized decision making and a lack of accountability/transparency are important contributing factors in the promotion and sustenance of corruption.

Case studies on regulation of the private sector in India (Bhat, 1997) find that:

1) Little effort is spent on implementing and enforcing rules and regulations

2) No policy exists to establish a common set of regulations for the private health care sector at the national level

3) Private providers resist accepting the applicability of certain regulations for their profession

4) Regulations have lost their relevance because they have not been revised

5) The private sector is not a high-priority on the government's policy agenda.

\subsubsection{Limitations of current regulatory practices}

Even though the private sector invariably plays a large role in the production and delivery of health goods and services, it does not receive due attention, which influences the child health outcomes. The government's focus on improving the performance of public sector providers is not sufficient for achieving health goals. Government policies can improve the quality and cost-effectiveness of private production and distribution (Buse, 2000). Current practices and regulations in developing countries restrict the private sector's ability to respond to the market, causing unnecessary delays in product registration processes, licensing, and certification. Some restrictions on the advertising of public health products discourage commercial sector participation in the production and marketing of public health commodities.

Governments sometimes control and constraint rather than allow the marketplace to function freely. For example, the Indian government developed a common label for ORS that commercial producers can use if they follow government product guidelines. The commercial sector, however, needs to differentiate its products (packaging, presentation, or appearance) in order to compete successfully (Rohde, 1997). Similarly, government overregulation is one of the most common constraints in motivating the commercial sale of ORS (O'Malley et al., 1990).

\subsection{Information Dissemination}

Information dissemination entails the use of both education and persuasion to change the behavior of providers as well as patients in ways that improve child health care services. This section discusses the prevailing strategies for information dissemination at policy, provider, and community level.

\subsubsection{Policy level strategies}

On account of the absence of relevant information about the extent and nature of private sector health care activities, the private sector receives little attention in policy formulation and implementation, even though it has a strong presence in the delivery and financing of health care services in developing countries. Government policymakers know little about the commercial sector; consequently, they unintentionally hamper the growth of the commercial market. Thus, availability and use of comprehensive information on commercial sector potential are extremely important in formulating health care policies.

Most developing countries lack information to foster communication and open discussion between the public and private sectors. Syntheses of existing and new information are necessary for effective planning. These syntheses should include:

* Analysis of sources and uses of government expenditures

* Examination of segments of the market by income, source of services, and child needs 
* Compilation of data on markets and market potential

* Examination of policies, laws, and regulations that affect private providers and commodity availability.

The availability of such information can facilitate analysis-based discussions of the respective roles of public, commercial, and NGO sectors. Information on the market can promote dialogue with the public sector and, consequently, help it identify segments of the child health market that truly need subsidized services.

USAID-funded POLICY Project activities in Brazil, the Central Asian Republics, Egypt, Ghana, Guatemala, India, Indonesia, Jamaica, Morocco, Philippines, and Turkey illustrate the value of sharing data in seeking private-public collaboration. For example, market segmentation studies served as centerpieces for discussions during meetings of public and private sector stakeholders in Turkey, Morocco, and Jordan. Stakeholders examined the findings, evaluated the efficiency of the current market structure, and discussed visions of a perfect market structure with a greater role for the private sector. Participatory analysis-based decision making facilitated private sector participation (Smith et al., 1998).

The POLICY Project facilitated an analysis-based policy dialogue among key stakeholders regarding private sector participation in Morocco and the Philippines. In some countries, POLICY successfully involved public and private entities in collection, analysis, and transmission of health care information.

UNICEF promoted information sharing and networking between government and NGOs in South Africa. It helped define roles in program implementation and adoption of bottom-up policies that defend children's rights. The process involved influencing national regulation, contributing to national thinking, and defining relationships between government and NGOs (Vanormelingen, 1999).

\subsubsection{Provider level strategies}

Various studies indicate the existence of gaps between knowledge and practices among private practitioners, misuse of antibiotics for the treatment of simple diarrhea, and improper instructions to clients regarding doses and other information (Murray et al., 1998). "Village doctors" provide a bulk of health care to sick children in rural areas of India. The doctors lack formal training and sources for up-to-date information. Governments have an important role to play in providing training to private sector providers. The private and public sectors can work together to improve knowledge and practices of public and private sector providers. For example, medical representatives, who are a major source of information about advances in treatment techniques and new products, have great potential to convince practitioners to change their prescribing behaviors.

A recent study conducted by Hudelson (1998) highlights several interventions undertaken to train private practitioners in integrated management of child health care. For example:

* In Bihar, private providers entered into a contract with NGOs regarding case management practices. After training, provider compliance with their contract was monitored and verified by consumer interviews (Chakraborty et al., 2000).

* In Kenya, shopkeepers were trained in dispensing antimalarials (AMs) and antipyretics (APs), advising purchasers how to administer AMs and APs, and referring patients to a health facility when appropriate to improve home management of childhood fevers.

* Training sessions for unlicensed drug retailers in Nepal and licensed drug retailers in Kenya, Indonesia, and the Philippines were organized to improve practices regarding dispensing drugs and advising and referring consumers. Moreover, providing training to traditional healers in South Africa and sub-Saharan Africa highlighted the possibility of improving the quality of services provided by village doctors.

All these experiences indicate remarkable improvements in the behavior and practices of private practitioners after undergoing tailored training sessions.

\subsubsection{Community level Strategies}

Health education and information sharing sessions are effective mechanisms for promoting healthy behaviors and creating demand for preventive care at the community level. These sessions mobilize and empower the community; identify, clarify, and communicate the benefits of healthy behaviors; and provide information on how 
and where to access assistance when problems arise. Various international NGOs successfully use IEC to organize and mobilize communities in Bolivia, Ethiopia, Guatemala, Honduras, Madagascar, and Malawi to promote sustainable change at the household and community levels in key child survival behaviors (Burkhalter 1997 and 1998; Salagado, 1998; Bhattacharyya, 1998; Alvarado, 1998; Sharma et al., 1998). Promoting healthy behaviors and creating demand for preventive care are highly cost-effective strategies in which NGOs can play a critical role.

\subsubsection{Generating demand for preventive health care}

IEC campaigns and NGOs help create demand for preventive services, which are critical to child health care and attractive to the for-profit sector. NGOs can integrate their ORT promotion and education efforts into the public health care system.

NGOs are generally involved in providing health education and creating demand for preventive health care. International NGOs, such as CARE and Save the Children, undertake a variety of relief, development, and technical assistance activities. Health education includes informing mothers about the health benefits of hand washing, breastfeeding, feeding during malaria, and so forth. NGOs also help health workers set up ORS depots, carry out health education activities (See Boxes 3.8 and 3.9), mobilize the community to launch preventive services such as immunization, and establish village health insurance systems (e.g., revolving drug fund) (Northrup, 1997).

These activities can also help get patients to participate in "regulation."

\subsubsection{Promoting healthy behaviors}

Behavior changes reduce morbidity and mortality considerably. Simple actions such as breastfeeding, appropriate complementary practices, basic hygiene practices, and a full course of infant vaccines help considerably to prevent childhood illnesses (Murray et al., 1997). Promoting healthy behaviors is a cost-effective intervention in which NGOs have an important role to play.

* Children born within two years of the previous child are at least twice as likely to die in the first year of life as those born after an interval of two years.

* As compared with infants who are breastfed exclusively, non-breastfed infants have a risk of death from diarrhea that is 14 times greater, a risk of death from respiratory diseases that is 4 times greater, and a risk of death from other infections that is 2.4 times greater.

* Nearly 3 million children die each year from vaccine-preventable diseases.

* Various studies document a reduction in malaria disease rates of 20 to 63 percent following the introduction of insecticide-treated mosquito nets.

* Numerous studies report that improving hand-washing practices with soap and an adequate volume of water can reduce overall diarrheal disease mortality by 30 to 50 percent.

* Mortality will likely decline 23 percent when vitamin A status rises to normal values

* Iodine deficiency is the world's greatest single cause of brain damage and mental retardation. Consumption of iodized salt is the most cost effective way to reduce iron deficiency.

* Correct application of ORS can reduce diarrheal mortality by 70 percent.

Efforts to promote healthy behaviors, combined with interventions to improve service quality and accessibility, can bring about remarkable improvement in child health care (See Box 3.10).

\section{Expanding the Role of the Private Sector in Child Health Care: Strategies and Instruments}

The available evidence suggests that usually the public sector is overextended and engaged in activities which could be done by the private sector. A clear assessment of the private sector can reveal areas where the private sector is already active and is contributing to sectoral objectives. In such cases, "easy-win" reform strategies may be developed for enabling growth in these sub-sectors. Such a strategy requires: identifying the easy-win sectors; identifying constraints to their enabling environment over which the government has influence; developing and implementing changes in the enabling environment - reducing barriers to entry, transaction costs, improving access to financing, inclusion in (public) referral systems, etc. 
The private sector has an enormous potential to help meet the increasing demand for high-quality child health care because it has large untapped sources. Some developing countries have been successful in leveraging this potential. The strategies and instruments they used are summarized in Table 4.1.

\subsection{Strategic use of resources-division of labor between the government and private sector}

Many countries are seeking strategies and solutions that will allow them to use both public and private sector resources and services efficiently and effectively. The central issues in determining an appropriate mix of public and private health care provision and financing are as follows:

* Defining which sets of services each sector can handle most effectively, and

* Ensuring that the work done in each sector complements the work done in the other.

An appropriate public-private mix must be found to increase equity or correct market failure. Public and private sector roles should consider country-specific conditions, including market size, demand for child health care, and the ability and willingness of consumers to pay for child health care. The two sectors must build an understanding of common objectives and complementary resources (see Box 4.1), taking into account the following factors:

1. The "Haves" versus the "Have-Nots": those who can and those who cannot afford to pay Various studies confirm that the government resources available for child health care services are not being targeted effectively (See Figure 4.1). Relatively wealthy patients are equally or more likely to use subsidized government health care than their less wealthy counterparts. By redirecting public funds to poor and hard-to-reach communities, the government can attract commercial sector interest. In this way, governments can complement rather than displace commercial sector efforts. Governments hold the ultimate responsibility to ensure accessibility and affordability of child health care services to the poor and the needy.

2. Rural and remote versus urban

The private sector usually serves the urban elite, who can afford to pay, as opposed to urban slum dwellers and rural populations, who may not be able to afford to pay. For example, in Tanzania, 78 percent of private for-profit units are located in urban areas (Munshi, 1997). Similarly, in Nepal and South Africa, 100 percent and 63 percent, respectively, of private hospital beds are in urban areas. In this case, NGOs and government sectors can assume responsibility for providing services to remote and rural areas.

3. Primary and preventive versus tertiary and curative care In Botswana, Gambia, Guinea, Namibia, Seychelles, Uganda, and Zimbabwe, tertiary care hospitals received a larger share of public sector health funds than did primary care facilities, indicating that more public sector funds are going toward curative health interventions, which tend to be more expensive and less cost-effective than preventive care. Figure 4.2 shows that in four of six countries, the richest group captures a greater share of primary health care spending than the poorest group.

Emphasis on commercial sector participation in production and distribution implies greater allocation of public resources to prevention and health promotion.

Other preventive services that NGOs can provide include demand generation and health education because NGOs are generally involved in educating mothers about the health benefits of hand washing, breastfeeding, and feeding during malaria. They can also inform community and health workers about how to set up ORS depots or carry out health education activities, mobilizing and organizing communities to launch preventive services such as immunization.

4. Public versus private goods and services

An analysis of DHS data of 11 countries shows lower use of private sector services for the more "public" goods, with significant demand-side market failures, such as immunization, and it shows higher use for private goods, such as treatment of childhood diseases (Berman et al., 1994).

Governments provide some public goods in the form of advocacy and information, research and development, 
subsidies for the poor, and specific services with substantial externalities, such as immunization and communicable disease control. In many cases, public goods focus specifically on the needs of children and complement essential health care services that could be provided by the private sector.

\subsection{Strategies to grow the private sector}

\subsubsection{Creating an environment for growth of the private sector}

By creating a favorable environment for the private sector and particularly for NGOs, governments and donors encourage greater NGO participation. The following strategies have been used to create an enabling environment for private sector growth in service delivery:

* The World Bank's NHP projects in Africa stimulated greater NGO participation. NGOs were given an important role in the World Bank-financed NHP projects, and their share of involvement in the projects increased from 43 percent in 1990 to 100 percent in 1996 (Elmendorf, 1999).

* In Malawi and Haiti, the MOH formally requested that Save the Children Federation (SCF) provide and manage provision of health services in general, and child health care in particular. The district assumed a regulatory role. $\mathrm{MOH}$ staff in Maissade were incorporated into the SCF community health team as much as possible. The program expanded to the regional level and served a population of 500,000 in 1993. SCF introduced and financed new programs, such as revolving drug funds, which later achieved self-sufficiency and are now managed by local health committees (Swedberg, 1999)

* Donor agencies are channeling an increasing amount of funds in developing countries through NGOs; for example, since 1998, 15 percent of overseas development aid filtered through NGOs (Buse, 2000).

* In 1999, the Global Alliance for Vaccines and Immunization (GAVI), a coalition of public and private interest groups, was formed to ensure that every child is protected against vaccine-preventable diseases. This coalition of governments, businesses, private philanthropists, and international organizations is working towards achieving at least 80 percent coverage under immunizations by 2005. Coalition participants are providing and managing a multimillion-dollar global fund for children's vaccines (WHO, 2000).

* In some countries, donors provided commodity support to nurture healthy commercial markets. For example, in Indonesia, USAID promoted the use of a leading soap, Lifebuoy, as a hand washing and hygiene product, thereby increasing its market share remarkably (Slater and Saade, 1996).

\subsubsection{Encouraging wealthier clients to use commercial sector services}

A desire for respect, dignity, and good standing in the community are very important motivating factors for the commercial sector to work in the social sector (Slater and Saade 1996). Government and donors play an important role in creating demand for private sector services by improving the image of private sector providers. This strategy is effective in encouraging wealthier clients to use commercial sector services (see Box 4.2). Other incentives for diverting wealthier patients to the private sector include user fees in public hospitals, restrictions on use of public services, and mandated inclusion of child health services in health insurance policies.

\subsubsection{Involving the private sector in promoting and selling child health care products}

Private sector distributors can prove effective in promoting and selling health related products directly to consumers. For example, the public sector's inability to distribute free ORS led to greater private sector participation in Pakistan. The sale of ORS packets increased from 10 million to 26 million during 1987-90 (See Figure 4.3) (Slater et al., 1996).

\subsubsection{Social marketing - subsidized products sold through commercial channels}

Distributors are getting involved in active social marketing of critical public health commodities. Products include ORS packets, soap for hand washing, insecticide-treated bed nets to prevent malaria (See Box 4.3), Vitamin A supplements, foods fortified with Vitamin A and iron, and vaccines (Northrup, 1997a). In Bolivia, collaboration between public and private health sectors succeeded in improving child health care: after realizing the limitation of its own distribution system, the government encouraged the private sector to participate in increasing and sustaining the ORS availability (Slater and Saade, 1996; Northrup 1997a; BASICS, 1999). 


\subsubsection{Using commercial product promotion and distribution channels}

Commercial product promotion and distribution networks can be used to make public health products such as ORS, insecticide-treated bed nets, iodized salt, iron supplements, chlorine bleach, and so forth, available to even the smallest retail outlets and information distribution systems. Developing countries are increasingly using commercial networks to distribute contraceptives. For example, in Andhra Pradesh, India, the State government signed a one-year Rs. 44 million contract with Hindustan Latex Limited to initiate a statewide social marketing program for condoms and ORS. Similarly, SIFPSA undertook a rural social marketing project with a private company (See Box 4.4).

\subsubsection{Delegating responsibility to NGOs for geographic areas, populations, or specific health services} NGOs often function like an additional arm of government by providing services in areas where government services are not available (See Box 4.5). In many cases, the government provides financial support to NGOs to provide additional services. Also NGOs can help identify problems and explore and test innovative solutions.

\section{Proposed Actions for Effective and Sustainable Private Sector Participation}

A comprehensive and integrated approach to child health care is required to harness the full potential of the private sector and find solutions beyond the public health system to meet growing child health care needs. All stakeholders - government, NGOs, the commercial sector, and households - need to share common concerns and actively participate to broaden policy dialogue; and develop a single sector policy (that addresses public and private sector issues), a common realistic expenditure program, common monitoring arrangements, and more coordinated procedures for funding and procurement (WHO, 2000).

Governments need to open communication channels with private sector health care providers and recognize the growing role that they play in child health care. Because of a scarcity of government resources, it is critical that resources not be spent on activities that the private sector performs. At the same time, government must support and manage the private sector so that it becomes a cost-effective alternative and encourages affordable health services.

\subsection{Formulation of conducive policy for private sector participation}

Although the private sector plays a critical role in the provision and financing of health care services, it is usually ignored in the formulation of health policy; consequently, policies and programs remain unrealistic and do not achieve the desired impact. Government can involve the private sector in a variety of ways, including sponsoring public-private stakeholder consultations, government-business roundtables, new forums, and so forth. Establishment of a private-NGO sector collaboration division in the Ministry of Health could go a long way in fostering the role of this sector. For example, in Egypt, NGO representatives are included by design on all government strategic planning teams to ensure that NGO interests are represented in strategic plans and that plans foster inter-sectoral collaboration. Similarly, in Ukraine, representatives of the government, NGOs, and the private sector formed a Policy Development Group, which organized meetings regularly to address legal and regulatory environment issues and develop a national reproductive health program for 2001-2005 (SAR7, 8, and 9).

\subsection{Role of partners, donors, and technical agencies in facilitating and guiding the government in private sector participation and development}

Governments and donors need to realize that there is an increasing dependence in developing countries on the private sector for both delivery and financing of health care services to meet health care challenges. In these countries, not only is there a lack of communication between government and donors, but there is also mistrust. Fostering communication and open discussion based on sound information is essential to improving publicprivate collaboration. For example, dialogue between policy champions and private sector players are critical to effectively implement rules and regulations.

Donors play an important role in facilitating greater private sector participation. Their influence can be used to bring about fundamental changes in health policies, such as reorientation of government health services toward 
the poor. International NGOs and donors can also help bridge the information gap by supporting research on markets and demand for child health care and sharing this information with the government and commercial sector.

\subsection{Capacity strengthening of public sector on stewardship function}

Good stewardship needs a better information base, an ability to build coalitions of support from different groups, and an ability to set incentives (WHO, 2000). For performing the stewardship function effectively, governments need proper systems in place and also skilled staff, which can be obtained through recruitment and through training and technical aid to existing staff. Effective public provision and financing systems are necessary to prevent undesirable market failures.

Stewardship requires a well thought out, analysis based policy, which recognizes and involves the private sector and assigns them roles. It involves setting system goals, identifying priorities, analyzing resource requirements, building consensus and informing people.

For exerting influence, governments require regulatory and advocacy strategies consistent with health system goals and the capacity to implement them cost-effectively. The regulatory and monitoring functions of the stewardship machinery will change in accordance with the policy. Regulation involves both the framing of rules to govern the behavior of the private sector and ensuring compliance with them. Generally lack of commitment, concern, and funds impede governments' capacity to carry out regulatory responsibilities effectively.

Governments need to build capacity in contracting skills and regulatory oversights. Design and implementation of regulatory oversight and contractual strategies involves high transaction cost in the beginning.

Governments need good intelligence systems, involving both information and understanding about the market, to perform the stewardship function effectively. The availability of such information can facilitate analysis-based discussions of the respective roles of public, commercial, and NGO sectors. Information on the market can promote dialogue with the public sector and, consequently, help it identify segments of the child health market that truly need subsidized services. Governments need the following:

* Analyses of National Health Accounts

* Information on segments of the market by income, source of services, and child needs

* Understanding of provider market structure and utilization patterns

* Understanding of policies, laws, and regulations that affect private providers and commodity availability

* Assessment of training needs

* Information on interventions offered by the private sector and their quality of services.

\section{Key Policy and Implementation Issues}

\subsection{Competition from Subsidized Products Can Crowd out the Private Sector}

The presence of large public sector programs that provide low-cost or free commodities and services strongly hinders the development of commercial markets. A study of 45 countries shows that strong government programs lead to small commercial presence (Rosen et al., 1999). With its highly subsidized commodities and services, the public sector usually crowds the commercial sector out of the child health market.

\subsection{People Seek Health Care from a Broad Range of Sources}

People seek health care from a broad range (public and private) of sources. Private providers are more popular for child health care. Informed choices involve trade-offs between cost, convenience, and amenity level on the one hand and technical quality-of-care on the other hand. Generally, the private sector responds better to the trade-offs perceived by patients (that is, the patient can perceive consumer quality, but not clinical quality).

\subsection{The Public and Private Sectors Could Be Competitors Too}


There are a number of alternative scenarios in which the public sector might work together with the private sector. The public sector is considered more equitable and the private sector more efficient. At times, the public and private sectors are seen as competitors, which may enhance efficiency of the health care system. However, government collaboration with the private sector has a better chance of improving coverage of public health services. Public-private competition is likely to be most successful in areas where "informational asymmetries are low and monopoly power [is] limited" (Bennett et al., 1997).

\subsection{The Quality of Services Provided by Private Health Practitioners Varies}

Private sector services are generally better in terms of consumer quality, but exhibit problems in clinical quality.

\section{i. Consumer Quality}

Private health care services are generally perceived to be of higher quality and more efficient than their public sector counterparts. However, the quality of services provided by private providers varies greatly and is difficult to monitor by the government. Accreditation of health service organizations by independent professional bodies may be worth considering in this respect.

\section{ii. Clinical Quality}

Numerous studies in developing countries report that the technical quality of care among private providers is inadequate. These studies reveal shortcomings in the private sector's case management practices for childhood illnesses (Chakraborty et al., 2000). Some common quality concerns include emphasis on profitable interventions as a result of supplier-induced demand; referral to the public sector for more complex and chronic cases; and neglect of preventive measures as a result of poor knowledge of consumers. For example:

* A comparative study of private and public sector services in Mexico revealed shortcomings in case management offered to children under the age of five with diarrhea and ARI. In general, the treatment offered by the public sector was better than that offered by the private sector (Bojalil et al., 1998)

* BASICS experiences in several countries revealed that the quality of private practitioners is woefully inadequate in those countries (BASICS, 1999)

* The private sector often neglects preventive measures because of poor knowledge of consumers, and it emphasizes profitable interventions that are not medically required (supplier-induced demand). A comparative analysis of public and private sector services in Malaysia indicates limited involvement of the private sector in the delivery of preventive services, raising serious quality concerns. For example, the private sector did not adequately maintain the immunization cold chain (Aljunid et al., 1997)

* Evidence of supplier-induced demand is widespread. A recent study by Thaver reports that there is widespread and excessive use of antibiotics and injections in Pakistan. Kenya, Pakistan, and Zambia also exhibited higher prescription rates of anti-diarrheal drugs by private providers (Bennett et al., 1997);

* A comparison of productivity indicators suggests no clear preference for public or private providers in urban Thailand. The public sector, however, treats more complex and chronic cases and is generally chosen by elderly patients; the private sector is more popular for children (Pannarunothai et al., 1997). The public sector has a clear price advantage for more expensive care (complex and chronic)

* In Pakistan, non-government physicians, uncertified doctors, healers, drug sellers, and other private sector practitioners treated about 84 percent of diarrhea cases (Northrup, 1993)

\subsection{The Public and Private Sectors' Priorities May Differ}

Public and private providers face different types of inducements and constraints. Consequently, both sectors allocate resources differently, and in turn produce different health outcomes and costs. Commercial motives, supplier-induced demand, and curative biases are largely responsible for the differing priorities.

Private providers respond to the population's willingness to pay. Hence, the private sector will undersupply the socially desirable services, such as immunization, to segments that may not be able to pay for them. Policymakers need to devise strategies to counter such tendencies and ensure proper delivery of public goods.

\subsection{Mobilizing the Commercial Sector Is Different from Mobilizing the Non-Profit Sector}

Mobilizing the commercial sector does not entail subsidizing production or funding a company's operations. Instead, it demands motivating commercial companies to take responsibility for sustainable production, and 
distribution and marketing of public health products. Usually, an initial inertia-breaking effort by governments and policymakers is required to support commercial ventures.

NGOs often function like an additional arm of the government by providing services in areas where government services are not available. In many cases, the government provides financial support to NGOs to provide additional services.

\subsection{Non-Economic Benefits Also Motivate the Private Sector}

Health care providers have both economic and non-economic motivating factors. Companies often fail to realize the public health potential of their products. A company's social responsibility can improve its image and attract more business. (See Box 6.1). Policymakers should also consider this factor while designing and implementing strategies that tap health care professionals' non-economic motivating factors.

A study conducted in slum areas of Pakistan reveals that private practitioners are eager and willing to provide preventive services (Thaver et al., 1997). A survey conducted by the NGO Initiatives reveals that personal financial rewards, professional autonomy, dissatisfaction with government bureaucracy, and a desire to help people are among the important motivating factors that drive health professionals to work in the private health care sector (Sclafani, 1997).

\section{Information Gaps and Future Study Needs}

The current report does not cover all areas and information gaps in the available research materials. Many unanswered questions remain, including the following:

- Does the participation of the private sector significantly lower government health care costs?

- What impact does higher private sector provision of child health care have on equity, access, quality, and cost of services?

- What are the advantages and disadvantages of contracting out preventive health care services?

- Can government and private networks complement each other to ensure a constant supply of public health products? Can they monitor the demand for such products?

Additional research studies are needed to fill these information gaps and enable policymakers to perform more effectively in their decision-making and deployment of child health care resources. Some research topics that need to be examined include:

- Strengths and limitations of market-based allocations in determining the volume and distribution of health services

- Non-regulatory means of influencing private sector behavior

- Impact of an open rating system on quality-of-care

- Types of contractual relationships between public and private providers

- Privatization options for the public sector, including hospital autonomy, internal markets, and performancerelated pay and contracts

- Effective approaches for improving the concern and commitment of service providers and determining the proper regulatory role of the government. Both the public and private sectors seem to suffer from a noticeable absence of genuine concern for the well being of those they are supposed to serve. Unless this problem is recognized and addressed, changing the sectors' roles may not bring about the desired improvements. In fact, services may deteriorate if governments increase the role of the private sector but take a heavy-handed approach in its regulation

- Design and development of a minimum regulatory package

- Impact of decentralization on the private sector and its capacity to form effective partnerships with the public sector

- Effect of privatization of primary health care

- Stakeholder analysis and reactions to increasing privatization

- Relative cost-effectiveness of using public funds to improve private provision versus strengthening the public sector itself 
Access to for-profit sector services by the poor, including the actual degree of current access and barriers; cost to the patients of "free" public sector services; per patient/service cost to the government compared with private sector costs; and the effectiveness and feasibility of a voucher system similar to American food stamps.

\section{Acknowledgments}

I am highly thankful to the Technical Advisory Group, comprising Drs. Harry Cross, William McGreevey, and Sagar Jain, for their critical review of my work and technical guidance. I am also grateful to Ms Varuni Dayaratna for providing useful comments for the improvement of the paper. I would also like to acknowledge support of April Harding and Sarbani Chakraborty. I received full support of Mark Hampton and Mariela Ohnemus among the library staff in the BASICS Library. I greatly appreciate Jen Meranberg's editorial support.

\section{Bibliography}

Aljunid, S.M., and A.B. Zwi. 1997. Public and private practitioners in rural district of Malaysia: Complements and substitutes? In Private health care providers in developing countries: serving the public interest? Edited by S. Bennet, B. McPake, and A.J. Mills. London: Zed Books; 40-53

Alvarado, V. 1998. Integrated care of the child in Honduras. In Community-based Approaches to Child Health: BASICS Experience To Date. Edited by M. Rasmuson, N. Bashir, and N. Keith. Arlington, VA: BASICS.

Bennett, S., B.I. McPake, and A.J. Mills. 1997. The public/private mix debate in health care. In Private health care providers in developing countries: Serving the public interest? Edited by S. Bennet, B. McPake, and A.J. Mills. London: Zed Books; 1-18

BASICS. 1999. Pathways and partnerships: BASICS contributions to child survival. Arlington, VA: Basic Support for Institutionalizing Child Survival.

Bennett, S. 1997. Health-care markets: Defining characteristics. In Private health care providers in developing countries: Serving the public interest? Edited by S. Bennet, B. McPake, and A.J. Mills. London: Zed Books; 85101

Berman, P. 1997. Supply-side approaches to optimizing private health sector growth. In Private health sector growth in Asia: Issues and implications. Edited by W. Newbrander. New York: John Wiley and Sons.

Berman, P., and L. Rose. 1994. The role of private providers in maternal and child health and family planning services in developing countries. Boston, Massachusetts: Data for Decision Making Project, Department of Population and International Health, Harvard School of Public Health.

Bhat, R. 1997. Regulation of the private health sector in India. In Private health sector growth in Asia: Issues and implications. Edited by W. Newbrander. New York: John Wiley and Sons.

Bhat, R. 2000. Initiatives to invite private capital through public-private partnerships in social sectors: Some experiences from the health sector. Vikalpa. 25(3); 37-48.

Bhattacharyya, K., J. Murray, W. Amdie, M. Asnake, M. Betre, P. Freund, T. Kedamo, W. Kereta, and P. Winch. 1998. Community assessment and planning for maternal and child health programs: A participatory approach in Ethiopia. Arlington, VA: Basic Support for Institutionalizing Child Survival.

Bloom, D.E. 1999. Public-private roles in providing and financing reproductive health care. WBI course on Adapting to Change: Reproductive Health and Health Sector Reforms. Washington, DC: The World Bank. Bojalil, R., H. Guiscafre, P. Espinosa, H. Martinez, M. Palafox, G. Romero, G. Gutierrz. 1998. The quality of private and public primary health care management of children with diarrhea and acute respiratory infections in Tlaxcala, Mexico. Health Policy and Planning 13(3): 323-331.

Broomsberg, J., P. Masobe, and A. Mills. 1997. To purchase or to provide? The relative efficiency of contracting out versus direct service provision of hospital services in South Africa. In Private health care providers in developing countries: Serving the public interest? Edited by S. Bennet, B. McPake, and A.J. Mills. London: Zed Books; 85-101

Burkhalter, B. 1997. Improving immunization coverage in Indonesia: An innovative NGO program. Child Survival BASICS. BASICS Quarterly Technical Newsletter 4:18-19

Burkhalter, B.R., and N. Bashir (eds.). 1998. Innovative approaches to child survival: Summaries of evaluation studies by La Leche League, Project HOPE, Project Concern, and World Relief. Arlington, VA: Basic Support for Institutionalizing Child Survival.

Buse, K., and G. Walt. 2000. Global public-private partnerships: Part 1-A new development in health? Bulletin of the World Health Organization; 78(4).

Chakraborty, S. 1998. Community monitoring of private providers in India: Results from an operations research 
study. In Community-based Approaches to Child Health: BASICS Experience To Date. Edited by M. Rasmuson, A. Bashir, and N. Keith. Arlington, VA: BASICS.

Chakraborty, S., AnnD'souza S., Northrup R. 2000. Improving private practitioner care of sick children: testing new approaches in rural Bihar. Health Policy and Planning; 15(4): 400-407.

Chakraborty S., Harding A. 2001. Conducting a private health sector assessment. The Private Sector HandbookChapter 2. Washington: The World Bank. (Draft paper)

Cuellar, C.J., W. Newbrander, and G. Price. 2000. Extending access to health care through public-private partnerships: The PROSALUD experience. Boston: Management Sciences for Health.

DeRoeck, D., and A. Levin. 1998. Review of financing of immunization programs in developing and transitional countries. Special Initiatives Report No. 12. Bethesda, Maryland: Partnerships for Health Reform Project, Abt Associates, Inc.

Elmendorf, E. 1999. The World Bank and NGOs in health sector reform: An operational perspective. In: the role of NGOs in health sector reform in developing countries. Report of a Policy Seminar. Washington, DC: Aga Khan Foundation USA.

Fabricant, S.T., C.W. Kamara, and A. Mills. 1999. Why the poor pay more: Household curative expenditures in rural Sierra Leone. International Journal of Health Planning and Management 14: 179-99.

Gilson, L., J. Adusei, D. Arhin, C. Hongoro, P. Mujinja, and K. Sagoe. 1997. Should African governments contract out clinical health services to church providers? In Private health care providers in developing countries: serving the public interest? Edited by S. Bennet, B. McPake, and A.J. Mills. London: Zed Books; 276-302. Gwatkin, D.R., S. Rustein, K. Johnson, R.P. Pande, and Wagstaff. 2000. Socioeconomic differences in health, nutrition, and population in India. HNP/Poverty Thematic Group of The World Bank. Washington, DC: The World Bank.

Hotchkiss, D.R., B. Kanjilal, S. Sharma, P.R. Sodani, and G. Chakraborty. 2000. Household expenditures on reproductive and child health care services in Udaipur, Rajasthan. Financing Reproductive and Child Health Care in Rajasthan. Indian Institute of Health Management Research and The POLICY Project. New Delhi: The POLICY Project.

Hudelson, P. 1998. Possible roles for non-government health providers in IMCI. Final Draft.

Krasovec, K., and R. Paul Shaw. 1999. "Reproductive health and health sector reform: linking outcomes to action". WBI course on Adapting to Change: Reproductive Health and Health Sector Reforms. Washington, DC: The World Bank.

Marek, T., I. Diallo, B. Ndiaye, and J. Rakotosalama. 1999. Successful contracting of prevention services:

Fighting malnutrition in Senegal and Madagascar. Health Policy and Planning 14(4): 382-389.

Muller, O., K. Cham, S. Jaffar, and B. Greenwood. 1997. The Gambian national impregnated bednet program:

Evaluation of the 1994 cost recovery trial. Social Science Medicine 44(12): 1903-1909.

Munshi, G.K. 1997. Private health sector in Tanzania: Private health sector growth following liberalization in Tanzania. Washington, DC: International Health Policy Program.

Murray, J., G.N. Adeyi, J. Graeff, R. Field, M. Rasmuson, R. Salgado, and T. Sanghvi. 1997. Emphasis behaviors in maternal and child health programs in communities. Arlington, VA: Basic Support for Institutionalizing Child Survival.

Murray, J., A. Mosazghi, B. Kifleyesus, and N. Orobaton.1998. Rural drug vendors in Eritrea: A study of practices and training needs. Arlington, VA: Basic Support for Institutionalizing Child Survival.

Musgrove, P. 1996. Public and private roles in health: theory and financing patterns. World Bank Discussion

Paper No. 339. Washington, DC: The World Bank.

Newbrander, W., and P. Moser. 1997. The future of health sector reform in Asia. In Private health sector growth in Asia: issues and implications. Edited by W. Newbrander. New York: John Wiley and Sons.

Northrup, R.S. 1993. "Reaching the private practitioner." PRITECH Issue Paper No. 2. Arlington, VA: PRITECH Project, Management Sciences for Health.

Northrup, R.S. 1997. Technical support of three activities for Indonesia, Jakarta and Yogyakarta, October 29November 9. Arlington, VA: Partnership for Child Health Care, Basic Support for Institutionalizing Child Survival.

Northrup, R.S. 1997. The private sector: critical partners in improving child health and survival. Child Survival BASICS. BASICS Quarterly Technical Newsletter 4: 1-9

O'Malley, G., and P. Spain. 1990. CDD Allies. PRITECH Field Implementation Aid. Arlington, VA: PRITECH and the Center for Development and Population Activities. 
O'Neill, C., and C. Saade. 1997. Mobilizing the commercial sector for child survival. Child Survival BASICS. BASICS Quarterly Technical Newsletter 4:14-17

Palmer, N. 2000. The use of private sector contracts for primary health care: Theory, evidence and lessons for low-income and middle-income countries. Bulletin of the World Health Organization 78(6): 821-829

Pannarunothai, S., and A. Mills. 1997. Characteristics of public and private health-care providers in a Thai urban setting. In Private health care providers in developing countries: serving the public interest? Edited by S. Bennet, B. McPake, and A.J. Mills. London: Zed Books; 54-70.

Rohde, J.E. 1997. Harnessing the private sector to serve public health: the case of ORS in India. Child Survival BASICS. BASICS Quarterly Technical Newsletter 4:1-3

Rosen, J.E., and S.R. Conly. 1999. Getting down to business: Expanding the private commercial sector's role in meeting reproductive health needs. Washington, DC: Population Action International.

Rosenthal, G. 2000. State of the practice: Public-NGO partnerships for Quality Assurance. LAC-HSR Health Sector Reform Initiative. Boston: Family Planning Management Development Project, Management Sciences for Health.

Rosenthal, G., and W. Newbrander. 1997. Public policy and private sector provision of health services. In Private health sector growth in Asia: Issues and implications. Edited by W. Newbrander. New York: John Wiley and Sons.

Salagado, R. 1998. Community-based mortality surveillance in Bolivia. In Community-based Approaches to Child Health: BASICS Experience To Date. Edited by M. Rasmuson, N. Bashir, and N. Keith. Arlington, VA: BASICS.

Sclafani, J.A. 1997. Private health care providers: ready to participate in child survival. Child Survival BASICS. BASICS Quarterly Technical Newsletter 4: 9-10

Semi-Annual Reports (SAR) 7, 8, and 9. 1999 and 2000. The POLICY Project. Washington, DC: The Futures Group International.

Sharma, S., R. Bhagat, and B. Kanjilal. 1998. Community managed health financing: A strategy for achieving livelihood security and sustainable health impact. New Delhi: CARE.

Sharma, S., W. McGreevey, and D.R. Hotchkiss. 2000. Financing reproductive and child health care in Rajasthan: Sources and uses of funding. Financing Reproductive and Child Health Care in Rajasthan. Indian Institute of Health Management Research and The POLICY Project. New Delhi: The POLICY Project.

Sharma, S., and D. Hotchkiss. 2001. Developing financial autonomy in public hospitals in India: Rajasthan's model. Health Policy 55(1).

Smith, J.M., R. Ritzenthaler, and E. Mumford. 1998. Policy lessons learned in finance and private sector participation. Working Paper Series No.2. Washington, DC: The POLICY Project, The Futures Group International.

Smith L, Brugha R, Zwi A. 2000. Working with private sector providers for better health care: an introductory guide. London: Options and DFID. (Draft paper)

Slater, S., and C. Saade. 1996. Mobilizing the commercial sector for public health objectives: A practical guide. Arlington, VA: Basic Support for Institutionalizing Child Survival.

Swedberg, E. 1999. Supporting health reforms in Malawi and Haiti. In The role of NGOs in health sector reform in developing countries. Report of a Policy Seminar. Washington, DC: Aga Khan Foundation USA.

Thaver, I.H., and T. Harpham. 1997. Private practitioners in slums of Karachi: professional development and innovative approaches for improving practice. In Private health care providers in developing countries: serving the public interest? Edited by S. Bennet, B. McPake, and A.J. Mills. London: Zed Books; 71-81.

UNICEF. 2000. The State of the World's Children 2000. New York: UNICEF.

Vanormelingen, K. 1999. NGOs and UNICEF: Possible lines of cooperation in health sector reform. In The Role of NGOs in Health Sector Reform in Developing Countries. Report of a Policy Seminar. Edited by C. Tanner and A. Lafond. Washington, DC: Aga Khan Foundation.

WHO. 2000. The World Health Report 2000. Health systems: Improving performance. Geneva, Switzerland: World Health Organization.

Winfrey, W., B. Kanjilal, S. Sharma, and D. Hotchkiss. 2000. The role of private sector in reproductive and child health service delivery in Rajasthan. In Financing reproductive and child health care in Rajasthan. Indian Institute of Health Management Research and The Policy Project, The Futures Group International.

World Bank. 1993. World Development Report, investing in health. Washington, DC: World Bank. 
World Bank. 1997. India new directions in health sector at the state level: An operational perspective. Population and Human Resource Division. South Asia Country Department II. New Delhi: World Bank.

Notes

i The private markets for child health care goods and services can be classified as:

* Commercial sector: (a) Distributors and wholesalers; retailers (pharmacies, medicine shops, supermarkets, corner groceries, etc.) are engaged in marketing and distribution of child health commodities including ORS packets, soap for hand washing, insecticide-treated bed-nets to prevent malaria, vitamin A supplements, foods fortified with vitamin A and iron, and vaccines, among others. (b) The commercial suppliers of health products include: pharmaceutical companies; soap manufacturers, marketers, and/or distributors; bed net manufacturers; chemical manufacturers (e.g. chlorine bleach); salt, sugar and other food manufacturers (can enrich their products with micronutrients, e.g. iodization of salt, fortifying flour with iron, vitamin A in sugar and dairy products); * Non-governmental organizations: Generally involved in health education, growth monitoring programs, providing preventive and curative services, promoting health behaviors, establishing village health insurance systems, motivating community to use vaccination facilities and mobilizing and organizing community to lunch preventive services.

* Private health providers: Engaged in treatment of childhood illnesses, providing diagnostic services, counseling and preventive and promotive services. 